\title{
PERSPECTIVAS TRANSNACIONAIS DA DIVERSIDADE ÉTNICO-RACIAL E CULTURAL NA FORMAÇÃO DE PROFESSORES ${ }^{1}$
}

\author{
Tatiane Cosentino Rodrigues ${ }^{2}$ \\ Ivanilda Amado Cardoso ${ }^{3}$ \\ Flavia Francchini ${ }^{4}$
}

\begin{abstract}
Resumo: Este artigo é um ensaio com dados parciais de pesquisa em andamento cujo objetivo é mapear o debate teórico sobre a questão da diversidade étnico-racial e cultural em diferentes contextos nacionais. Metodologicamente o artigo apresenta um levantamento sobre o lugar da diversidade cultural no campo da formação de professores de forma articulada entre Brasil, França e EUA. Tal debate apresenta-se como dimensão fundamental em virtude das novas configurações que tornam as análises em termos nacionais obsoletas. Desse modo, espaços nacionais que vivenciaram suas configurações de nação como colonizador ou colonizado veem recrudescer os conflitos em torno das populações refugiadas e em situação de migração que desafiam a lógica da identidade nacional que balizou a formação dessas nações. Os desafios contemporâneos situam-se nos modos de governamento e de convivência nesses espaços. Assim, cabe reposicionar o debate em torno do lugar da cultura e do pertencimento étnico-racial nos processos educacionais.
\end{abstract}

Palavras-chave: Relações étnico-raciais, educação, formação de professores, diversidade cultural

\section{TRANSNATIONAL PERSPECTIVES OF ETHNIC-RACIAL AND CULTURAL DIVERSITY IN TEACHER TRAINING}

\footnotetext{
${ }^{1}$ Pesquisa em desenvolvimento com financiamento da Fundação de Amparo à Pesquisa do Estado de São Paulo-FAPESP e Coordenação de Aperfeiçoamento de Pessoal de Nível Superior-CAPES. Trata-se de uma proposta de pesquisa documental e bibliográfica em desenvolvimento na Universidade Paris Nanterre no Centre de recherches en éducation et formation - CREF, em colaboração com o Grupo de Estudos Education familiale et interventions socialies auprès des familles.

${ }^{2}$ Professora Adjunta IV do Departamento de Teorias e Práticas Pedagógicas e do Programa de PósGraduação em Educação. https://orcid.org/0000-0002-4402-2805. E-mail: tatiane.cosentino@ gmail.com

${ }^{3}$ Mestre e doutora pelo Programa de Pós-Graduação em Educação da UFSCar, bolsista CNPq. E-mail: ivanildaamado@gmail.com

4 Mestre pelo Programa de Pós-Graduação em Educação da UFSCar, bolsista CAPES. https://orcid.org/0000-0002-8305-8851.E-mail: flavia.franccchini@gmail.com
} 
Abstract: This article is an essay with partial data from ongoing research whose objective is to map the theoretical debate on the issue of ethnic-racial and cultural diversity in different national contexts. Methodologically, the article presents a mapping about the place of cultural diversity in the field of teacher education in an articulated way between Brazil, France and the USA. Such a debate presents itself as a fundamental dimension due to the new configurations that make analyzes in national terms obsolete. In this way, national spaces that experienced their configurations as a colonizer or colonized nation see the conflict around refugee populations and those in a situation of migration intensify that refute the logic of national identity that marked the formation of these nations. Contemporary challenges lie in the modes of governance and coexistence in these spaces. Thus, it is necessary to reposition the debate around the place of culture and ethnic-racial belonging in educational processes.

Keywords: ethnic-racial relations, education, teacher training, cultural diversity

\section{PERSPECTIVAS TRANSNACIONALES DE LA DIVERSIDAD ETNICO-RACIAL Y CULTURAL EN LA FORMACIÓN DE PROFESORES}

Resumen: Este artículo es um ensayo com datos parciales de investigaciones em curso cuyo objetivo es mapear el debate teórico sobre el tema de la divesidad étnico-racial y cultural en diferentes contextos nacionales. Metodológicamente, el artículo presenta una encuesta sobre el lugar de la diversidad cultural en el campo de la formación docente de manera articulada entre Brasil, Francia y los Estados Unidos. Tal debate se presenta como una dimensión fundamental debido a las nuevas configuraciones que hacen que los análisis en términos nacionales sean obsoletos. De esta manera, los espacios nacionales que experimentaron sus configuraciones como colonizador o nación colonizada ven el conflicto en torno a las poblaciones de refugiados y aquellos en una situación de migración se intensifican y refutan la lógica de identidad nacional que marcó la formación de estas naciones. Los desafíos contemporáneos radican en los modos de gobernanza y convivencia en estos espacios. Por lo tanto, es necesario reposicionar el debate sobre el lugar de la cultura y la pertencia étnico-racial en los procesos educativos.

Palabra clave: Relaciones étnico-raciales, educación, formación del profesorado, diversidad cultural.

\section{PERSPECTIVES TRANSNATIONALES DE LA DIVERSITÉ ETHNIQUE-RACIALE ET CULTURELLE DANS LA FORMATION DES ENSEIGNANTS}

Résumé: Cet article est un essai avec des résultats partielles de recherches en cours dont l'objectif est de cartographier le débat théorique sur la question de la diversité ethnique-raciale et culturelle dans différents contextes nationaux. Méthodologiquement, l'article présente une enquête sur la place de la diversité culturelle dans le domaine de la formation des enseignants de manière articulée entre le Brésil, la France et les USA. Un tel débat se présente comme une dimension fondamentale du fait des nouvelles configurations qui rendent obsolète l'analyse en termes nationaux. De cette manière, les espaces nationaux qui ont connu leur configuration de colonisateur ou de nation colonisée voient le conflit autour des populations réfugiées et des personnes en situation de migration s'intensifier, réfutant la logique d'identité nationale qui a marqué la formation de ces nations. Les défis contemporains résident dans les modes de gouvernance et de coexistence dans ces espaces. Il est donc nécessaire de repositionner le débat autour de la place de la culture et de l'appartenance ethnique et raciale dans les processus éducatifs.

Mot clés: relations ethno-raciales, éducation, formation des enseignants, diversité culturelle 


\section{INTRODUÇÃO}

Este artigo se alia ao trabalho que está sendo desenvolvido no âmbito de dois outros projetos, do Programa Abdias Nascimento/CAPES, edital que contemplou com bolsas de mobilidade nove estudantes de graduação e doutorado autodeclarados negros da UFSCar com pesquisas na Colômbia, França e EUA e à pesquisa em desenvolvimento, financiada pelo CNPq/Edital Universal, intitulada "Transnacionalismo e proposta curricular para a educação das relações étnico-raciais e da diferença no ensino ${ }^{5}$ " em que atuo como pesquisadora e que pretende elaborar uma plataforma digital de conteúdos voltados para a educação básica e ensino médio nesta temática.

Em conjunto, estes projetos configuram um esforço de continuidade e aprofundamento de três dimensões que estão presentes na agenda de pesquisa em que estamos trabalhando no Núcleo de Estudos Afro-Brasileiros (NEAB/UFSCar) e grupo de pesquisa Educação e Relações Étnico-Raciais/CNPq.

A primeira dimensão corresponde à interlocução entre educação e raça/discriminação racial, que está relacionada à relevância da luta contra as desigualdades raciais como um aspecto para se pensar a democratização da educação, que como direito social deve garantir o direito à diferença e enfrentar o desafio de implementar políticas que superem as desigualdades raciais e sociais.

A segunda dimensão está relacionada ao quadro de mudanças na atuação do Estado brasileiro em relação a esta temática, incentivadas pelas constantes proposição e reivindicação do movimento negro por políticas públicas comprometidas com a superação da discriminação racial, especialmente a partir da mobilização deste movimento social, em sua pluralidade de atuação e organização no processo de discussão e elaboração da Constituição de 1988, assim como da mudança da Lei de Diretrizes e Bases da Educação Nacional pelas leis n. $10.639 / 03^{6}$ e n. $11.645 / 08^{7}$ que tornaram obrigatório o ensino de história e cultura afro-brasileira, africana e dos povos indígenas em todos os níveis da educação brasileira.

\footnotetext{
${ }^{5}$ Coordenação de Anete Abramowicz, Universidade de São Paulo.

${ }^{6}$ Estabelece em 9 de Janeiro de 2003, a obrigatoriedade da temática "História e Cultura Afro-Brasileira".

${ }^{7}$ Modifica a lei 10.639 em 10 de Março de 2008, incluindo a obrigatoriedade da temática "História e Cultura Afro-Brasileira e Indígena".
} 
A terceira dimensão a que este trabalho se refere diretamente a um momento político posterior, a experiência de implementação de uma disciplina obrigatória sobre a temática étnico-racial no curso de Pedagogia da Universidade Federal de São Carlos, instituição que possui um histórico de vinte e oito anos no debate das relações étnicoraciais, em virtude da significativa trajetória do NEAB/UFSCar em processos de formação inicial e continuada de professores nesta temática.

Esta disciplina focaliza a educação das relações étnico-raciais como dimensão indispensável à Didática, campo de investigação da ciência Pedagogia, que estuda meios, instrumentos, modalidades, estratégias utilizadas para ensinar e aprender, situando-os histórica, social e culturalmente. Em síntese, partindo do pressuposto de que a didática tem como princípio a distribuição democrática do saber, e tem a responsabilidade social de acompanhar e refletir as mudanças que ocorrem no mundo e dar respostas para a ressignificação dos processos de ensino e aprendizagem, a didática das relações étnicoraciais pode ser compreendida como o campo da didática que responde à necessidade de se considerar o pertencimento étnico-racial, a cultura e a identidade como constituintes do processo de ensino e aprendizagem.

Objetiva, ainda, construir experiências de formação em que os participantes possam vivenciar, analisar e propor estratégias de intervenção em que se busquem valorizar culturas que constituem a nação brasileira, eliminar práticas racistas e discriminatórias, criar condições para a convivência respeitosa, nos termos das leis e Diretrizes pertinentes a este campo.

Os professores são considerados agentes de fundamental importância na superação das iniquidades étnico-raciais e na promoção de uma educação de qualidade. Tal fato tem provocado mudanças curriculares na formação inicial de professores, como a inclusão de disciplinas obrigatórias concernentes a esta temática, no entanto, duas questões centrais ainda ecoam nas pesquisas sobre a temática e nos núcleos de pesquisa que têm em muitas instituições discutido estas mudanças curriculares: será que os/as professores/as estão sendo de fato preparados/as, nos cursos de formação inicial de professores/as, para lidar pedagogicamente com situações de discriminação racial e para a valorização da diversidade racial e cultural? Que metodologias, estratégias e práticas as experiências em voga têm apresentado como eficazes?

Estes questionamentos fazem parte de uma agenda de pesquisa e ação mundial que se aprofunda com os fluxos migratórios e consequentemente com composições 
sociais cada vez mais diversas na cultura, etnia, religião e racialmente. A concentração de trabalhos nesta área temática no último encontro da WERA (World Education Research Association), realizado de 03 a 05 de agosto de 2018, na África do Sul (Cape Town), exemplifica como a formação de professores, o currículo e o acompanhamento dos indicadores de acesso e permanência à educação escolar no mundo estão/são atravessados pela questão da diversidade cultural, de gênero e étnico-racial.

Uma primeira análise dos títulos e resumos dos trabalhos submetidos resultou num total de 87 trabalhos de 538 trabalhos enviados sobre a temática da diversidade cultural e étnico-racial, tendo prevalecido instituições de pesquisa dos EUA, Alemanha, Itália, Suécia, Canadá, Chile, Peru, Espanha, África do Sul, Reino Unido, Jamaica, Índia, México, França, Hong Kong, Nova Zelândia, Pensilvânia, Brasil e Suécia.

Assim, estudos com dimensões comparativas em Educação sobre a presença e papel da diversidade cultural e étnico-racial, com foco na formação inicial de professores são fundamentais em contextos cada vez mais configurados por situação de refúgio e fluxos migratórios como os que temos na contemporaneidade. Junto ao contexto de aprofundamento das desigualdades sociais, enfraquecimento das democracias ao redor do mundo e emergência de governos conservadores que opõem diversidade étnica, cultural e/ou racial à qualidade da educação.

\section{A FORMAÇÃO DE PROFESSORES E EDUCAÇÃO DAS RELAÇÕES ÉTNICO-RACIAIS NO CONTEXTO BRASILEIRO}

A introdução da temática "diversidade étnico-racial" na produção teórica sobre os processos de formação de professores começou a aparecer timidamente a partir dos anos 1990. Atualmente, embora ainda seja restrita, há um crescente número de pesquisas nessa área como demonstram André et.al. (1999), Andrade (2007), Paula; Guimarães (2014) e Corenza (2018).

No caso brasileiro, as pesquisas têm mostrado que o preconceito e discriminação raciais são parte do cotidiano de crianças, jovens e adultos/as que frequentam as escolas. As práticas discriminatórias se iniciam na educação infantil, como mostra Cavalleiro (2000); continuam no primeiro e segundo ciclos do ensino fundamental, respectivamente, $1^{\mathrm{a}}$ a $4^{\mathrm{a}}$ séries, como demonstra Algarve (2004) e entre a $5^{\mathrm{a}}$ e $8 / 9^{\mathrm{a}}$ séries, como analisa Souza (2001); persistindo no ensino médio, como afirma Andrade (2006). 
Mesmo que de forma indireta a questão da formação de professores começa a ser indicada nos trabalhos sobre a questão étnico-racial e a escola, principalmente em trabalhos realizados no cotidiano das escolas. Gonçalves (1987), verifica a existência de um ritual pedagógico que marginaliza crianças e jovens negros. Para o autor, trata-se do ritual do silêncio. Silêncio ${ }^{8}$ dos professores perante as situações de discriminação impostas pelos livros didáticos e que ignora as relações estabelecidas no espaço escolar (GONÇALVES, 1985, p. 28).

De forma geral, o silêncio dos professores em relação às situações de discriminação é resultado em parte da ausência desta temática nos cursos de formação, principalmente de formação inicial e pelo ainda influente discurso da democracia racial que supõe que no Brasil não há racismo.

A sistematização e análise dos trabalhos produzidos sobre a temática formação de professores e relações étnico-raciais indica que há um crescente na produção sobre o tema, mas ainda uma cisão entre os estudos de formação de professores e relações étnicoraciais que se aprofunda no debate sobre a formação inicial de professores. $O$ acompanhamento dos trabalhos apresentados nas Reuniões Anuais da Associação Nacional de Pós-Graduação (ANPED) ilustra esta assertiva, nos Grupos de Trabalho Formação de Professores (GT 08) e Relações Étnico-Raciais e Educação (GT 21), de 2003 a 2017 considerando os resumos dos trabalhos e pôsteres disponíveis on line notase que os trabalhos sobre este tema se concentram no GT 21, tendo a educação em geral como foco mas em menor número o tema da formação inicial de professores como objeto central das análises.

No GT de Formação de Professores foram identificados quatro trabalhos sobre o tema (COUTO, 2003; ANDRADE, 2003; XAVIER, 2007 e MARIANO, 2009). De forma geral são trabalhos que por meio de análises documentais e bibliográficas introduzem o debate sobre multiculturalismo e diversidade cultural na educação. Xavier (2007) buscou observar o impacto de um curso de formação continuada que abordou temas como multiculturalismo e pluralidade cultural na perspectiva crítica de Peter MacLaren. Mariano (2009), apresenta um mapeamento bibliográfico sobre multiculturalismo e formação de professores considerando a produção publicada na

\footnotetext{
${ }^{8} \mathrm{O}$ ritual do silêncio será retomado e retrabalhado em pesquisas posteriores como a de Coelho (2007) intitulada "Só de corpo presente: o silêncio tácito sobre cor e relações raciais na formação de professores do Estado do Pará.
} 
ANPED, ENDIPE e periódicos avaliados como nacional e internacional A. Segundo o autor, os dados permitem inferir que a formação de professores analisada a partir da perspectiva multicultural ainda é uma área pouco explorada. Constatou-se a predominância de estudos sobre diversidade cultural, o que para o autor, indica uma frágil presença do multiculturalismo nos estudos sobre a formação docente.

Para este levantamento foram considerados os trabalhos de Brzezinsk e Garrido (2001) e Brzezinski (2007) por serem trabalhos de análise e síntese das pesquisas publicadas no GT. No período de 1992 a 1998, segundo as autoras os trabalhos foram organizados nas categorias Formação Inicial de Professores, Formação Continuada, Profissionalização Docente, Práticas Pedagógicas e Revisão de Literatura. No enquadramento proposto pelas autoras faltam, de acordo com o levantamento, trabalhos sobre a carreira docente e aos movimentos de valorização profissional, sobre o perfil do formador de professores e tampouco foram levantados dados sobre como outros profissionais veem os professores ou como os alunos veem os docentes.

No período de 1999 a 2003 as autoras caracterizam a produção nas seguintes categorias: Formação Inicial, Formação Continuada e Desenvolvimento Profissional Docente, Saberes Docentes Aprendizagem Profissional, Profissão Docente e Identidade Profissional, Profissionalização e Socialização Docente e Outros.

No mapeamento dos anos 1990 foram apontados como temas silenciados: a dimensão política na formação do professor, a formação do professor para atuar em movimentos sociais, na educação de jovens e adultos, na educação indígena e para lidar com a diversidade cultural. Nos anos 2000 o quadro não mudou significativamente, há ainda poucos trabalhos sobre estes temas, outros temas emergentes são, segundo as autoras, professores de cursos superiores, condições de trabalho, principalmente questões sobre a saúde dos docentes e a educação a distância em cursos de formação de professores.

No GT 21, com foco específico na formação de professores foram identificados dois trabalhos (SISS, 2005 e ASSIS, 2008), embora sejam poucos trabalhos sobre o tema com foco na formação de professores é importante salientar que os trabalhos do GT se concentram na escola de educação básica com foco no currículo, livros didáticos, perfil dos professores, políticas de ação afirmativa, práticas pedagógicas e formação continuada de professores. No artigo intitulado "Formação docente e a temática étnico-racial na Revista Brasileira de Educação da ANPED (1995-2015), os autores Almeida et. al. (2018) 
destacam que dos 33 artigos identificados sobre o tema no recorte temporal proposto, 26 foram publicados a partir de 2001, ano da criação do GE 21, "Relações Raciais/Étnicas e Educação" na ANPED. Dos 7 artigos que antecederam esse período, 4 deles foram publicados no ano de 2000, o que se coaduna com os processos de mobilização durante a década de 1990, que conduziram a efetivação do GT 21 na ANPED, em 2003. Da mesma forma, o período entre 2003 e 2008 representa a transição entre a homologação das leis n. 10.639/2003 e 11.645/2008, e com isso, a estruturação de vários processos analíticos nessa área de conhecimento.

Com destaque para a relação da formação de professores e a temática étnicoracial, evidenciou-se que, anteriormente ao ano de 2000, as publicações da RBE não mencionaram processos de formação inicial e/ou continuada de professores/as nessa área de conhecimento, destacando também que do total de 7 publicações sobre formação docente, 1 data do ano de 2000 e as outras 6, a partir de 2005, o que indica a influencia manifestada pelas mudanças na LDB com a introdução da obrigatoriedade do ensino de história e cultura dos povos indígenas, afro-brasileiros e africanos.

Com intuito de mapear a produção nacional sobre formação de professores, foram localizados artigos, teses e dissertações que se propuseram a realizar balanços dentro do recorte temático "formação de professores e relações étnico-raciais". Assim, identificaram-se os seguintes trabalhos: Monteiro, (2010), Silva, (2010), Xavier de Paula e Guimarães, (2014), Silva (2014), Coelho, Santos e Silva (2014).

Ao realizar um levantamento no Banco de Teses e Dissertações da CAPES, entre 2001 e 2005, Rosana Monteiro (2010) identificou quatro ${ }^{9}$ trabalhos que abordaram as relações raciais e a formação de professores, sendo duas teses e duas dissertações desenvolvidas na UFSC, UFF (2006) UFBA e UFRN. Segundo Monteiro (2010), dentre os quatros trabalhos encontrados, o mestrado de Santos (2003) é o único que aborda as relações étnico-raciais no curso de Pedagogia.

Para sua dissertação de mestrado, Silva (2010) também realizou levantamento bibliográfico da produção de teses e dissertações em cinco universidades públicas e

\footnotetext{
9 Clemêncio, M.Ap. Identidades e etnias na educação: a formação de professores do magistério em Florianópolis. SC: UFSC, 2001. Mestrado; Assis, M.de P. A questão racial na formação de professores na perspectiva dos docentes da FFP. RJ: UFF, 2006. Mestrado; Jesus, R.de C.D.P. de como tornar-se o que se é: narrativas implicadas sobre a questão étnico-racial, a formação docente e as políticas para equidade. Salvador: UFBA, 2007. Doutorado; Coelho, W.de N. B. A cor ausente: um estudo sobre a presença do negro na formação de professores. RN: UFRN, 2005. Doutorado.
} 
particulares do estado de São Paulo, entre os anos de 1988 e 2008. As universidades pesquisadas foram PUC-SP, UFSCar, UNESP, USP e UNICAMP, sendo as fontes de pesquisa os próprios bancos de dados das instituições. Silva (2010) identificou 16 pesquisas que articularam os temas relações étnico-raciais e formação de professores/as, entre os níveis de doutorado e mestrado. Dentre essas 16 pesquisas identificadas, apenas 2 trataram sobre formação inicial de professores isoladamente.

No artigo "10 anos da lei federal 10.639/03 e a formação de professores: uma leitura de pesquisas cientificas", os autores de Xavier de Paula; Guimarães (2014) desenham um importante "estado da arte" sobre a formação de professores para a educação das relações étnico-raciais no Brasil. Os autores utilizaram como fonte de investigação os relatórios de pesquisas consolidados no Banco de Teses e Dissertações da CAPES e a plataforma de artigos científicos indexados na SCIELO.

Como procedimentos metodológicos, Xavier de Paula; Guimarães (2014) realizaram uma concisa análise crítica das referências bibliográficas e documentais. Os resultados da análise evidenciam que até o ano de 2000 a formação de professores não tinha visibilidade, uma crescente demanda pelo tema de pesquisa, ocorre em anos posteriores. Foram analisadas 12 teses de doutorado e 15 dissertações de mestrado, e dentre estes trabalhos, sete pesquisas abordaram formação inicial: duas teses de doutorado, Jesus (2007) e Monteiro (2010); e cinco trabalhos de mestrado, Santos (2003), Silva (2009), Pinheiro (2009), Oliveira (2010) e Silva (2013).

Coelho; Santos e Silva (2014) também realizaram um consistente levantamento e análise das teses e dissertações brasileiras relacionadas à temática da educação e relações raciais. As autoras recensearam trabalhos defendidos no período de 2000 a 2010, dentro dos Programas de Pós-Graduação em Educação (PPGE), avaliados com conceitos 04, 05 e 06 (CAPES), distribuídos nas instituições federais de Ensino Superior, diferentes regiões do País e nos Grupos de Pesquisa cadastrados no CNPq.

No artigo de Coelho, Santos e Silva (2014), constata-se que há um número restrito de produção de pesquisas sobre educação das relações raciais defendidas no Brasil, sendo que dentre o total de 98 dissertações e teses, 16 abordaram a formação de professores. $\mathrm{O}$ levantamento não detalha a formação de professores em suas modalidades inicial e continuada.

Jesus (2007), na tese intitulada "De como tornar-se o que se é: narrativas implicadas sobre a questão étnico-racial, a formação docente e as políticas para a 
equidade", realiza uma discussão acerca da formação inicial de professores em dois cursos da Universidade Federal da Bahia (UFBA), tomando como base as perspectivas multireferencial, multicultural e o pensamento anticolonial da educação, analisando a inserção da questão étnico-racial nos currículos a partir das políticas para a equidade adotadas pela instituição. Para a autora, a história de vida é uma análise do processo de formação profissional, a partir de um empreendimento historiográfico, com ênfase nos aspectos de inserção social e cultural da Pedagogia e da educação (Jesus, 2007).

A dissertação de Santos (2007) teve como objetivo apreender qual a compreensão dos graduandos em Pedagogia sobre o racismo, preconceito e discriminação racial. Fundamentando-se no arcabouço teórico sobre formação de professores e racismo na literatura nacional, a pesquisa adotou como procedimento metodológico a aplicação de entrevistas semiestruturadas e realizou a análise de um caso de ensino. Os participantes da pesquisa foram alunos do Curso de Pedagogia que atuavam na Educação Básica e, segundo a autora, os graduandos demonstravam significativa compreensão sobre os conceitos apresentados, apontando a inexistência de discussões no curso sobre diferenças étnico-raciais, gênero, religião e orientação sexual. As conclusões da autora chamam a atenção para a importância dada às formas de discriminação na formação de professores.

A tese de Monteiro (2010) intitulada "A educação para as relações étnico-raciais em um curso de Pedagogia: estudo de caso sobre a implantação da Resolução CNE/CP 01/2004", é uma importante contribuição para as discussões sobre a formação inicial de professores e educação das relações étnico-raciais.

A autora teve como enfoque analisar se e como a implantação das DCNs-ERER vinham ocorrendo e em que medida isso contribuiu para a formação de profissionais da educação capazes de romper com a reprodução das ideologias ainda operantes relacionadas ao racismo, no contexto da sociedade capitalista contemporânea. O universo da pesquisa foi o Curso de Pedagogia de uma universidade privada, a Universidade São Francisco- Bragança/SP (USF - Bragança).

Na pesquisa, Monteiro (2010) realizou uma revisão das reivindicações históricas do Movimento Negro no campo educacional desde a década de 1930, suscitando reflexões acerca das concepções neoliberais e suas influências nas políticas educacionais e, também questionando as políticas de formação de professores/as centradas no modelo tecnicista que priorizam disciplinas de metodologias e técnicas, o que para a autora poderiam restringir-se aos “modos de fazer". Para Monteiro (2010), esta perspectiva tem 
sérias implicações na formação de professores para a educação das relações étnico-raciais, uma vez que para combater o racismo na escola, os docentes precisam compreender os mecanismos do mesmo dentro da sociedade brasileira.

Sob a perspectiva gramsciana, Monteiro (2010) afirma que a Pedagogia do "aprender a aprender" tem como base uma educação cognitiva, fortemente divulgada pela Declaração de Jontiem (UNESCO, 1990). Para a autora, aquela Pedagogia constitui-se em um dos obstáculos para a educação das relações étnico-raciais e dificulta o alcance das demandas do movimento social negro, pois, "simplificam a formação escolar produz o esvaziamento de conteúdos, enfatizam a metodologia de ensino como mera técnica e a colocam no lugar de conteúdo, reforçam o individualismo, focalizam o imediato e o útil dentre outras possibilidades" (MONTEIRO, 2010, p. 232).

O conjunto de pesquisas encontradas e descritas acima, nos permitem visualizar uma crescente produção científica e a diversidade de problemas de pesquisas relacionados à temática da formação de professores e relações étnico-raciais com diferentes linhas de discussões e metodologias, entretanto, quando se refere à formação inicial e, principalmente, ao curso de Pedagogia, há uma produção ainda escassa, sobretudo, em pesquisas de doutorado (MONTEIRO, 2010; SILVA, 2010).

Diante do apanhado de contribuições teóricas apresentadas acima podemos discutir as repercussões do ensinar e aprender na perspectiva das relações étnico-raciais. No contexto de sociedades multiculturais como a nossa, a abordagem sobre o tema é ampla, vasta e permite muitas aproximações, mas a construção de uma proposta de educação das relações étnico-raciais nos cursos de pedagogia e licenciatura como prevê as Diretrizes ERER, deve ser realizada como construção coletiva. Os cursos devem ser construídos a partir da interação de professores e estudantes levando-se em consideração as suas experiências de vida.

Silva (2009) observou em pesquisa com professores de biologia que a construção de conhecimentos e saberes a respeito das relações étnico-raciais no Brasil ocorre nas experiências vividas no âmbito da família, da comunidade, da prática docente, no contato com a mídia. $\mathrm{O}$ autor ressalta que é na experiência que os processos educativos, ao longo da vida, geram conhecimentos, valores e são perpassados por ideologias que orientam as relações vividas com as outras pessoas (SILVA, 2009, p. 190). Se o processo de construção de conhecimentos e saberes é permeado por experiências, como demonstrou Silva (2009) e outros autores, que têm se dedicado à pesquisa sobre saberes docentes, 
como por exemplo, Tardif (2002) e Nóvoa (1995), é de suma importância que os cursos de formação inicial reservem tempo e espaço para a socialização e discussão desses saberes e que estes possam ser problematizados durante o curso.

Um dos grandes desafios relacionado à formação de professores, tendo como base normativa as Diretrizes ERER é a superação de uma situação que Gomes (2008) caracteriza como de desequilíbrio, pois se há de um lado iniciativas de formação continuada promovidas pelo poder público, pelas universidades, pelos movimentos sociais, de outro lado, a discussão ainda não ocupa um lugar central nos currículos de graduação do país. Os cursos de pedagogia ainda mantêm uma estrutura curricular de caráter disciplinar, gradeada e fechada à introdução dessas e de outras questões reivindicadas pelos movimentos sociais.

O desequilíbrio nos currículos de formação inicial e em relação aos cursos de formação continuada expressa o quanto a formação de professores ainda precisa avançar. $\mathrm{Na}$ avaliação de Gomes (2008) o desequilíbrio revela a tensão entre as diferentes interpretações e tendências nos debates e nas práticas de formação inicial e continuada de professores da educação básica. Essa tensão expressa o predomínio de um tipo de racionalidade que impera nos meios acadêmicos e afeta a formação docente.

\section{OS ESTUDOS SOBRE DISCRIMINAÇÃO ÉTNICO-RACIAL NA EDUCAÇÃO FRANCESA ${ }^{10}$}

\footnotetext{
10 Paris tornou-se um importante espaço para o desenvolvimento do que foi denominado de internacionalismo negro. Entre os anos 1919 e 1925, nos deparamos com o surgimento da Liga das Nações, a realização de três congressos Pan-africanos $(1919,1921,1923)$, um importante encontro da Universal Negro Improvement Association (UNIA). No mesmo período, outra iniciativa, em 1922, articula a criação do Institut d'Ehnologie de Paris por Marcel Mauss, Paul Rivet e Lucien Lévy-Bruhl.
}

Paris foi considerada uma espécie de capital cultural mundial tornando-se palco e o cenário para recepção da ideia de existência de um New Negro materializada desde o início em distinções tais como afroamericans (africanos americanos de descendência anglo-saxonica) e afro-latins (africanos-latinos nascidos nos países coloniais latinos, por exemplo, nas colônias francesas), os últimos supostamente experimentando formas racistas sutis de convivência social. Surgiu, também, a proposta de um tipo de pesquisa etnológica que estava preocupada coma produção de conhecimento sobre homens de hoje e de homens fósseis, os últimos, seres fossilizados como uma alusão não mais a uma diferença biológica, mas a formas culturais arcaicas que guardariam proximidades com a pré-historia dos europeus.

Desta forma, as ciências sociais desenvolvidas no âmbito da colonização, a partir do final do primeiro quarto do século XX, organizaria a sua transição: um primitivo inferior biologicamente para um primitivo culturalmente arcaico conformando-se uma nova forma de dominação, que desloca o discurso normalizador da diferença com base na hierarquia biológica evolucionista, para uma concepção pluralista ambientalista com ênfase na diversidade cultural (SILVÉRIO, 2018). 
Por décadas a legislação escolar francesa não conferiu tratamento específico às singularidades dos públicos escolares, sejam elas linguísticas, culturais ou étnico-raciais. Segundo Francis (2015), a orientação assimilacionista da escola francesa explica porque ela permaneceu por tanto tempo indiferente às diferenças, decorrente em parte de uma tradicional abordagem sociológica de tradição marxista que essencialmente acentuou as relações de classe e as desigualdades ligadas a critérios socioeconômicos (FRANCIS, 2015, p. 119).

A partir da década de 1990, os estudos sobre discriminação ainda focados na dimensão do gênero e deficiência desenvolveram-se no contexto francês, evitando termos como raça/racial, vistos ainda como um tabu nos contextos educativos.

Num primeiro período, os estudos sobre os contextos e as trajetórias escolares dos filhos de imigrantes ressaltaram a "etnização" da escola e as discriminações étnicas (PAYET, 1995, 1997, 1998; LORCERIE, 1999). Seguidos por estudos que ressaltaram a questão da violência e segregação escolar por dificuldades socioeconômicas, mas sobretudo presente nas experiências de famílias de nacionalidade francesa ou não, de países como Ásia, África e das Antilhas (DEBARBIEUX; TICHIT, 1997; DEBARBIEUX; GARNIER; MONTOYA; TICHIT, 1999).

Embora estes temas já tivessem lugar na produção intelectual negra desde a Présence Africaine e da Négritude, na década de 1960, esses debates adquiriram força renovada no contexto político e se refletiu no campo acadêmico de produção, de forma mais acentuada a partir dos anos 2000. Neste momento há a constituição de uma determinada política racial na França cujas consequências imediatas puderam ser vistas por um lado, por potencializar um campo renovado de estudos e pesquisas. E, por outro lado, por operar um desvio no cerne do que constitui a narrativa da república francesa que reconhece, de modo semântico, apenas indivíduos e não grupos (NDIAYE, 2006, p. 95). Essa configuração política permitiu que houvesse na França certa "etnização da questão social" cuja inflexão teórica reflete problemáticas anteriormente debatidas na dimensão social e passam a ser analisadas em dimensões étnicas (FASSIN e FASSIN, 2010).

A partir dos anos 2000, os trabalhos na educação passam a focar a amplitude da segregação étnico-racial em certos estabelecimentos escolares relacionados a crianças cujos pais fizeram um percurso migratório (FELOUZIS; LIOT; PERROTON, 2005). Além disso, a questão étnica foi igualmente colocada em evidência por estudos 
aprofundados sobre a violência escolar (LORCERIE; PHILIPP, 2002). Quando das reuniões de orientação, na categoria dos motivos citados como causas potenciais de tratamento desfavorável por jovens adultos tendo efetuado seu percurso escolar na França, a cor da pele figura em segundo lugar, depois da origem (BRINBAUM; MOGUEROU; PRIMON, 2010). As discriminações pautadas em critérios étnicos e raciais das práticas de orientação escolar e nas formações profissionais são confirmadas pelos trabalhos conduzidos por Dhume (2011).

No caso francês, são os significados da identidade nacional francesa que são questionados pela "fratura colonial" tendo a escola como lócus específicos de eclosão destes conflitos (BLANCHARD, et. all., 2006). Dito de outra maneira, as construções discursivas do Estado-nação francês são colocadas em relevo a partir da entrada das "minorias" no espaço francês.

Segundo Francis (2015) a recepção deste tema se dá em duas principais frentes, a da pesquisa em si mas especialmente na de formação dos atores da educação, professores e profissionais da educação, na formação inicial e continuada, que sempre focaram a questão da desigualdade mas não a de discriminação (FRANCIS, 2015, p. 121). Tal fato, tem colocado o Institut Français d'Education (Instituto Francês de Educação), uma instituição importante que substituiu o Institut National de la Recherche Pédagogique INPR (Instituto Nacional de Pesquisa Pedagógica) em um impasse em como enfrentar a questão da discriminação na formação inicial e continuada de professores, entre desigualdade ou problemas ligados à etnicidade ou etnização.

Duas legislações contemporâneas tornam o cenário francês mais complexo em relação à temática central deste projeto, quais sejam: a integração no direito francês da diretiva europeia 2000-43 de 29/06/2000 pela igualdade de tratamento entre as pessoas sem distinção de raça ou de origem étnica e o reconhecimento da questão das discriminações raciais, o que tem encorajado os órgãos públicos a desenvolverem ações de luta contra os preconceitos e os estereótipos raciais, e a promoverem a educação para a diversidade (DIM, 2012). A segunda legislação refere-se à aprovação, em 2011, da lei n. 2001-434 que reconhece "o comércio negreiro e a escravidão como crimes contra a humanidade", também conhecida como lei Taubira, em referência à autoria de Christiane Taubira, ministra da justiça da França de 2012 a 2016, sob a presidência de François Hollande.

A lei estabelece em seu primeiro artigo que a República Francesa reconhece que

Revista da ABPN • v.12, n $^{\text {o } 32} \cdot$ março - maio 2020, p. 68-96 
o comércio negreiro transatlântico assim como no Oceano Índico de um lado, e a escravidão por outro lado, cometidos a partir do século XV nas Américas, no Caribe, no Oceano Índico e na Europa contra os povos africanos, indu-americano, malgaxes e índios constituem um crime contra a humanidade.

Além deste reconhecimento, a lei prevê em seu artigo segundo que além dos programas de ensino escolares e dos programas de pesquisa em história e ciências humanas conferirem importância ao comércio negreiro e à escravidão, deve-se estabelecer, favorecer e estimular uma cooperação que permita relacionar os arquivos escritos disponíveis na Europa com fontes orais e conhecimentos arqueológicos acumulados na África, nas Américas, no Caribe e em todos os demais territórios que padeceram da escravidão.

Segundo Fassin (2002), tardiamente, depois de muitos países a França “descobriu” a discriminação racial, e não se pode atribuir este fato apenas à imigração, mas à forma como determinados grupos foram construídos como Outros, já que a pessoa discriminada, geralmente é francesa, nasceu na França. Para o autor, este reconhecimento tardio exige uma renovação das categorias usadas para pensar a realidade social e a questão da discriminação racial deve ser analisada de forma mais ampla e não restrita às políticas de imigração. Para o autor, a questão da discriminação racial se enquadra no quadro analítico da desigualdade e da justiça social (FASSIN, 2002, p. 410).

\section{OS ESTUDOS SOBRE EDUCAÇÃO, FORMAÇÃO DE PROFESSORES E DIVERSIDADE CULTURAL E ÉTNICO-RACIAL NO CONTEXTO ESTADUNIDENSE}

No contexto estadunidense a discussão sobre educação e diversidade étnico-racial possui um histórico de décadas devido ao processo de mobilização e reorganização do sistema educacional empreendidos pelo movimento dos direitos civis.

As pedagogias culturalmente relevantes (LADSON-BILLINGS, 1995) e culturalmente responsivas (GAY, 1994) fizeram parte das reformas educacionais dos processos de formação inicial de professores. Tal fato, não significa que o debate encontra-se encerrado ou que não existam diferentes perspectivas teóricas e práticas de como efetivar estas mudanças, mas sim, que há um acúmulo significativo de pesquisas que reúnem resultados e análises destes processos, como por exemplo as pesquisas sobre 
os impactos destas pedagogias nos indicadores de desempenho ou no aumento/envolvimento de alunos em diferentes áreas de conhecimento, como as ciências matemática e/ou biológicas (CASTAGNO \& BRAYBOY, 2008). Assim, como trabalhos que desafiam a área da gestão escolar e da formulação das políticas educacionais a empreender mudanças neste sentido, em conjunto com o trabalho dos professores.

Os primeiros levantamentos e estudos realizados sobre multiculturalismo e educação nos Estados Unidos levaram ao trabalho de James Banks como um dos principais teóricos da educação nessa temática. $\mathrm{O}$ autor possui um número expressivo de livros acadêmicos, de formação de professores e paradidáticos publicados que são considerados referência e orientam os currículos das escolas regulares e de formação de professores.

Em 1992, o autor tornou-se o primeiro diretor do Centro para Educação Multicultural da Universidade de Washington, e seu trabalho foca na educação para a cidadania e diversidade num contexto global que é, segundo o autor, extensão do trabalho que iniciou de educação para cidadania nos EUA no início da década de 1980 (BANKS, 2006, p. 10). Banks (1986), no livro "Educação Multicultural nas sociedades ocidentais", desenvolveu uma análise e visão geral das respostas ao pluralismo cultural de países que dividiam a mesma estrutura sociopolítica, econômica e compromisso ideológico com a democracia e igualdade. Para Banks, quando se analisa o desenvolvimento de revitalização étnica nas sociedades ocidentais democráticas como Estados Unidos, Canadá, Reino Unido e Austrália e as respostas que as instituições educacionais formularam, pode-se criar paradigmas. Com frequência, a primeira fase da resposta das escolas à reivindicação de grupos étnicos consistiu na inclusão de blocos de conteúdos sobre grupos étnicos no currículo, especialmente nos cursos de humanidades, estudos sociais e linguagem.

A celebração de feriados étnicos e o ensino sobre heróis se destacam nesses programas aditivos (id., 1986, p. 11). No que se refere aos nomes adotados, Banks (1994) afirma que os programas relacionados à educação étnica com frequência são conceituados de forma diferente e conhecidos por uma variedade de nomes, incluindo educação multirracial, educação multiétnica, educação multicultural e educação antirracista. Educação multicultural é o termo usado nos Estados Unidos, Reino Unido, Canadá e Austrália, e educação intercultural é o termo usado frequentemente nas nações europeias, incluindo França, Alemanha, Holanda e Suíça. 
Para Banks, dois movimentos importantes precedem a formação da educação multicultural: o movimento de educação intergrupo e o movimento de estudos étnicos. Segundo ele, em 1930 um movimento educacional emergiu nos Estados Unidos para ajudar estudantes imigrantes a se adaptarem à vida nos Estados Unidos, a se tornarem cidadãos "efetivos". Como na educação intercultural, os objetivos da educação intergrupo focaram a minimização das culturas e filiações étnicas pautada no ensino da tolerância étnica e racial (id., 1992, p. 231). O movimento de educação intergrupo emergiu como uma resposta aos violentos conflitos raciais que ocorreram no início da década de 1940. Escolas e universidades que formavam professores foram pressionadas a criar unidades institucionais, projetos e atividades para responder à crise racial na nação (id., ibid., p. 279).

Nomeado também de educação intercultural, o movimento intergrupo entrou em decadência com o acirramento dos conflitos raciais e a emergência dos direitos civis que se contrapuseram à proposta de educação intercultural. O segundo movimento, designado por Banks de estudos étnicos, ou Black Studies, emergiu em 1960 e 1970 e está diretamente ligado ao movimento dos direitos civis. (BANKS, 2004, p. 10).

Segundo Banks (2004), o movimento de educação intergrupo é um importante antecedente do movimento corrente de educação multicultural, mas não a sua principal raiz. O movimento corrente está mais diretamente ligado aos estudos étnicos iniciados por estudiosos como W. E. B. DuBois (1935), Woodson (1919/1968), Bond (1939) e Wesley (1935). Os principais arquitetos da educação multicultural foram influenciados pelos estudos afro-americanos e estudos étnicos relacionados a outros grupos minoritários nos Estados Unidos. A evolução do movimento multicultural Baker (1977), J. A. Banks (1973), Gay (1971) e Grant (1978) têm um papel significativo na formulação e desenvolvimento da educação multicultural nos Estados Unidos.

A educação multicultural é compreendida por Banks em quatro fases. A primeira fase da educação multicultural emergiu quando educadores que tinham interesses e especializações em história e cultura de grupos étnicos específicos iniciaram ações individuais e institucionais para incorporar os conceitos, informações e teorias dos estudos étnicos na escola e no currículo de formação de professores. Assim, a primeira fase do multiculturalismo é nomeada de estudos étnicos e refere-se à década de 1960, quando afro-americanos demandaram a formação de um número maior de professores negros e a reescrita dos livros didáticos para melhor refletirem a história e cultura afro- 
americana. Nos Estados Unidos, outros grupos como mexicanos e indianos fizeram exigências semelhantes.

Os estudos étnicos dominaram a primeira fase da educação multicultural nos Estados Unidos, porém alguns educadores envolvidos no movimento dos estudos étnicos começaram a compreender que o conteúdo étnico era necessário, mas não uma condição suficiente para reestruturar as escolas, para fazer com que estudantes de diferentes grupos étnicos e raciais vivenciassem a igualdade (BANKS, 1992, p. 282). A segunda fase da educação multicultural, segundo Banks, emergiu, desse contexto, quando esses educadores propuseram que a escola se reformasse e respondesse às necessidades específicas de estudantes negros e ajudasse todos os alunos a desenvolverem atitudes raciais e étnicas mais democráticas. A educação multiétnica foi a segunda fase da educação multicultural, com o objetivo de trazer mudanças sistemáticas e estruturais para o total da escola. Uma terceira fase da educação multicultural emergiu com outros grupos que viam a si mesmos como vítimas da sociedade e das escolas, como as mulheres e pessoas com deficiência, e demandaram a incorporação de suas histórias, culturas e vozes no currículo, na estrutura das escolas, colégios e universidades. A quarta e corrente fase da educação multicultural é o desenvolvimento de teorias, pesquisa e práticas que relacionam categorias como raça, classe e gênero. É importante notar que cada fase da educação multicultural continua hoje. No entanto, as fases finais tendem a ser mais proeminentes que as primeiras na teoria e na prática (id., ibid., p. 285). Na atual fase de desenvolvimento do multiculturalismo, Banks (2004) afirma que um dos principais objetivos desse movimento é a reforma das escolas e outras instituições educacionais, de forma que estudantes de diversos grupos, racial, étnico e classe social, vivenciem a igualdade educacional. Outro importante objetivo da educação multicultural é oferecer a estudantes meninos e meninas a chance de vivenciá-la com igualdade de sucesso e de mobilidade educacional.

A educação multicultural tem como objetivo também a criação de uma cultura e estado-nação unificados, mas respeitando e reconhecendo a diversidade. Objetiva criar um estado-nação em que os valores dos diversos grupos e culturas serão refletidos, o que se resume para Banks em "criar uma sociedade de pessoas diversas unidas por valores democráticos" (id., 1994, p. 50). Ainda segundo Banks (1979), a educação multicultural sugere um tipo de educação relacionado com uma faixa ampla de grupos culturais. 
Banks afirma que, de forma geral, os teóricos multiculturalistas acreditam que o currículo deve refletir as culturas de vários grupos étnicos e a cultura nacional compartilhada. Os estudantes precisam estudar todas essas culturas com o objetivo de se tornarem participantes efetivos e elaborar decisões em uma nação democrática pluralista. “O currículo deve respeitar a etnicidade de estudantes e usá-la em um sentido positivo. No entanto, a escola não deve forçar os estudantes a serem e sentirem etnicamente se eles escolheram se libertar do pertencimento e fidelidade étnica" (id., ibid., p. 130). O pressuposto geral é que, num processo de múltipla aculturação, os elementos étnicos estão sendo universalizados, e, nesse processo, a escola deve ajudar os estudantes a desenvolverem três tipos de identificação inter-relacionadas: étnica, nacional e global. Consequentemente, a escola não deveria estar preocupada em apenas ajudar os alunos a desenvolverem identificações étnicas, nacionais e globais, mas a adquirir competências que Banks denomina de cross-cultural (transversal).

Equilíbrio entre unidade e diversidade Segundo Banks (2006), o equilíbrio entre unidade e diversidade é um contínuo desafio para as nações multiculturais. Unidade sem diversidade resulta em hegemonia e opressão, diversidade sem unidade conduz a um rompimento/fratura no estado-nação. Um dos principais problemas enfrentados pelos Estados no mundo é como reconhecer e legitimar a diferença e ainda construir uma identidade nacional que incorpore as vozes, experiências e expectativas dos diversos grupos que a compõem. Muitos grupos étnicos e religiosos têm fracas identificações com seu estado-nacão devido à situação de marginalização e porque eles não veem suas expectativas, sonhos e possibilidades refletidas dentro do estado-nação ou escolas, colégios e universidades (LADSON-BILLINGS in BANKS, 2004, p. 208). A diversidade trazida para a Europa por seus imigrantes de ex-colônias tem aumentado a tensão e conflito étnico, racial e religioso. Como a imigração está crescendo em todo o continente, os Estados estão procurando formas de balancear unidade e diversidade. As noções assimilacionistas de cidadania são ineficazes hoje devido à profundidade da diversidade pelo mundo e às exigências de grupos marginalizados por reconhecimento cultural e direitos. A cidadania multicultural é essencial para a era global atual, conforme atesta Kymlicka (1995), que reconhece e legitima o direito e a necessidade dos cidadãos de manterem compromissos com suas comunidades culturais e com a cultural cívica nacional. Banks reitera a preocupação de Nussbaum (2002) em atestar que nós deveríamos ajudar os estudantes a desenvolver cosmopolitismo. Cosmopolitas veem a si 
mesmos como cidadãos do mundo que poderão tomar decisões e ter ações que promovem a democracia e a justiça social. Cosmopolitas se identificam com pessoas de diversas culturas do mundo. Compreendem a justiça social de forma global e estão preocupados com as ameaças da comunidade global, como o aquecimento global, epidemia de HIV/AIDS e desenvolvimento sustentável. Na perspectiva de Banks, os estudantes devem desenvolver um equilíbrio delicado entre as identificações cultural, nacional e global. As experiências culturais, nacionais e globais são interativas e interrelacionadas de uma forma dinâmica.

Mattai (1992), no artigo Rethinking the nature of multicultural education, argumenta que a educação multicultural e para a diversidade não elimina ou não lida diretamente com o racismo, trata-se apenas de uma medida paliativa. Para o autor, três aspectos importantes devem ser considerados sobre a educação multicultural: a) a questão da definição, b) eficácia da educação multicultural em mudar a situação de grupos desvalorizadosno sistema educacional e c) se o multiculturalismo ressalta a questão do racismo na sociedade americana ou circunscreve esta questão a outras categorias. Em diferentes áreas de pesquisa, esses autores compartilham a compreensão de que diversidade se dissociou da raça e de que tal fato mantém e perpetua a injustiça racial. Swartz sintetiza essa premissa ao afirmar que "a procura por diversidade sem raça tornouse um mantra que se opõe e desmantela as políticas de ação afirmativa ao mesmo tempo em que não desafia a importância histórica e contínua de raça como um fator que sustenta a hierarquia de identidade e valores humanos" (SWARTZ, 2009, p. 1047). Em oposição aos padrões de restrição que a diversidade hegemônica defende, Swartz propõe um modelo emancipatório construído com dogmas desenhados pelas

A tese da autora é a de que as novas exigências, operando à guisa de “oportunidades iguais" (mas sem distribuição equitativa de recursos), estão reproduzindo resultados desiguais para os que não são tão bem servidos pelo sistema educacional. Esta previsível diferença/distância reflete a falência da sociedade em resolver os persistentes problemas de hierarquia racial e hegemonia cultural que engendram debates na educação na última década. Essas irrupções na academia sobre o currículo coincidem com as lutas comunitárias contra o racismo na educação - resistência ostensiva a livros multiculturais e esforços para incluir a linguagem afro-americana nas escolas. Embora o campo de batalha pareça diferente, as discordâncias em décadas precedentes sobre o cânone literário, sobre o que deve ser ensinado nas escolas e sobre as transformações curriculares entre 
liberais, progressistas e conservadores são instrutivas. Mesmo que a sociedade estadunidense pareça mais "diversa", a análise que permanece para os Black Studies e Black Education é a de que a práxis da educação está pautada em formas de conhecimento que sustentam resultados racializados injustos e desiguais (KING, 2004, p. 350)

\section{CONSIDERAÇÕES}

Nosso objetivo ao mobilizar os três contextos (brasileiro, francês e estadunidense) não foi o de esgotar ou realizar uma análise comparativa entre os mesmos, mas ilustrar as diferentes condições de emergência e os desafios que estão colocados para uma mudança epistemológica no campo de formação de professores no Brasil e em outros países, na construção de uma didática das relações étnico-raciais, que rompa com a dicotomias entre o escolar e não-escolar, o político e o cultural, entre fundamentos e metodologias ainda presentes em vários currículos e práticas de formação professores.

Sabe-se mais hoje sobre a influência dos professores na aprendizagem e desempenho dos alunos, há também uma literatura consistente destacando os saberes docentes, epistemologia da prática docente (SHON, 1983, SHULMAN, 1987), identidade do professor (DAY, 2004, KORTAGHEN, 2004). Se o processo de construção de conhecimentos e saberes é permeado por experiências, como demonstrou Silva (2009) e outros autores, que têm se dedicado à pesquisa sobre saberes docentes, como por exemplo, Tardiff (2002) e Nóvoa (1995), é de suma importância que os cursos de formação inicial reservem tempo e espaço para a socialização e discussão desses saberes e que estes possam ser problematizados durante o curso

Em um ensaio sobre o assunto, Tardiff (2001) traz à tona a necessidade de maior articulação entre os saberes dos cursos de formação continuada e os saberes docentes. Ainda que implícitas, as preocupações com a diversidade cultural puderam ser identificadas quando o autor enfatiza que esses saberes deveriam ter implicações sobre o respeito e a apreciação aos outros, destacando que a lógica disciplinar deveria dar lugar a outras lógicas, que considerassem suas crenças, culturas, e modos de ver o mundo, bem como ligasse esses componentes à socialização profissional docente, ela própria mobilizadora de questionamentos identitários e éticos.

Assim, uma das propostas que indicamos é justamente a de pensar o campo da formação de professores e o campo das relações étnico-raciais de maneira articulada. Isto 
é, pretende-se problematizar as relações étnico-raciais como matriz da formação inicial de professores, articulando estes campos cujas trajetórias revelam até aqui diálogos escassos.

A inserção de disciplinas obrigatórias sobre o tema nos currículos de formação inicial tem sido uma das principais iniciativas, importante, mas insuficiente para uma mudança epistemológica que atravesse todo o processo de formação, comumente nas experiências de formação nos deparamos com relatos de que há domínio conceitual sobre, por exemplo racismo, discriminação, alteridade, identidade mas total despreparo para trabalhar com situações cotidianas sobre os temas, assim como afirmações de que o primeiro encontro com o tema ocorreu na disciplina obrigatória. Nos seis anos de obrigatoriedade desta disciplina na UFSCar não é raro que os alunos afirmem que é a primeira vez na vida que compartilham espaços com estudantes negros.

Para Silva e Gomes (2002) o maior desafio para o campo da didática e da formação de professores e pensá-la na sua dinâmica e articulação com os processos educativos e não transformá-la em metodologias e técnicas de ensino para os ditos "diferentes e diversos". Isso significa tomar a diferença como constituinte dos processos educativos.

Em relação às propostas que se intitulam de interculturalismo, multiculturalismo ou transculturalismo, como destacamos, estas definições respondem aos diferentes contextos, mas em comum guardam o fato de que surgiram em resposta à mobilização e denúncia de grupos que passaram por processos e experiências de racialização, ou seja, é importante considerar que não é possível trabalhar com a ideia de trocas culturais quando alguns grupos não têm a sua humanidade reconhecida.

Neste momento, junto ao acompanhamento dos diferentes projetos em curso é urgente a organização e a luta pela manutenção desta agenda junto à defesa pela educação, o direito à educação está ameaçado em vários contextos nacionais, nos encontramos em meio a um ataque às ciências, em especial às ciências humanas, a um projeto de formação de professores, à um projeto de educação democrática que colocava como possibilidades a ampliação de oportunidades para crianças e jovens, negros, indígenas e pobres, criando um novo horizonte de expectativas de futuro.

Em 2002 realizou-se a Conferência Ethinic Diversity and Citizenship Education and Diversity Conference na Itália, que reuniu um grupo de pesquisadores de diferentes países para identificar os problemas e questões relacionados ao estabelecimento de uma 
educação cívica capaz de promover participação cívica para todos os grupos no interior do estado-nação e o respeito por suas diferenças culturais. Os trabalhos apresentados na Conferência foram reunidos por James Banks no livro Diversity and citizenship education: global perspectives (2004), que é finalizado com o trabalho de Walter Parker, em que propõe o desenvolvimento de um currículo global para o estabelecimento de uma educação pautada na cultura global. Para tanto, cinco temáticas foram apresentadas para a composição desse currículo: historiografia, estudos constitucionais comparativos, estudos étnicos comparativos, estudos comparativos sobre pobreza e deliberação (PARKER, 2004, p. 441). Na área de historiografia, o autor propõe que histórias de todos os tipos e de diferentes lugares precisam ser contadas e ouvidas, "a imaginação das crianças precisa ir além das fronteiras de sua família e comunidade imediata", o autor também ressalta a importância do trabalho com autobiografias na historiografia. Nos estudos constitucionais comparativos, o autor sugere que os alunos tenham oportunidade para comparar os discursos correntes sobre o significado de democracia, soberania popular, direitos individuais, antirracismo e os diferentes significados que democracia assumiu em realidades políticas locais distintas (id., ibid., p. 446). Os estudos étnicos comparativos são dedicados ao entendimento do conceito de diversidade ao redor do globo, compreendendo as diferenças culturais, políticas, estéticas, religiosas, econômicas e o significado de etnia em diferentes Estados.

\section{REFERÊNCIAS BIBILIOGRÁFICAS}

ALGARVE, Valéria Aparecida. Cultura Negra na sala de aula: pode um cantinho de Africanidades elevar a autoestima de crianças negras e melhorar o relacionamento entre crianças negras e brancas? Dissertação (Mestrado). PPGE, Universidade Federal de São Carlos, São Carlos, 2004

ALMEIDA, Neil F. P; AMÂNCIO, Márcia H.; SANTOS, Sérgio P.; SALES, Leydiane V. Formação docente e a temática étnico-racial na Revista Brasileira de Educação da ANPED (19952015). Revista Brasileira de Educação, v. 23, 2018.

ANDRADE, Maria Celeste de M. Cidadania, cultura e diferença na escola. $26^{a}$ Reunião Anual da ANPED, Poços de Caldas, 2003

ANDRADE, Paulo. S. Pertencimento étnico-racial e ensino de História. São Carlos, 2006, 179p. Dissertação (Mestrado) PPGE, Universidade Federal de São Carlos, São Carlos, 2006. 
ANDRADE, Roberta Rotta Messias de. Pesquisas sobre formação de professores: uma comparação entre os anos 90 e 2000. 30ª Reunião Anual da ANPED, Caxambu, 2007.

ANDRÉ, Marli; SIMOES, Regina H.S.; CARVALHO, Janete. Et al. Estado da Arte da Formação de Professores no Brasil. Educação \& Sociedade, ano XX, vol.20, nº 68, p.301-309, 12/1999.

BAKER, G. Multicultural education: Two preservice approaches. Journal of Teacher Education, 28, 31-33, 1977.

BANKS, James A. African American Scholarship and the Evolution of Multicultural Education. Journal of Negro Education. V. 61, n. 3, 1992. Disponível em: http://www.jstor.org/stable. Acessado em: Outubro de 2009.

BANKS, James A. Shaping the Future of Multicultural Education. Journal of Negro Education. V. XLVIII, n. 3, 1979. Disponível em: http://www.jstor.org/stable. Acessado em: Outubro de 2009.

BANKS, James; LYNCH, James. Multicultural education in western societies. New York: Praeger Publishers, 1986.

BANKS, James; BANKS, Cherry A. McGee. Multicultural education: issues and perspectives. Bicentennial, 2007.

BANKS, James. Multhiethnic education: theory and practice. Boston: Allyn and Bacon, 1994. Educating citizens in a multicultural society. New York: Teachers College Press, 1997. An introduction to multicultural education. Boston: Allyn and Bacon, 2002.

2006. Race, culture and education: the select works of James A. Banks. Oxon: Routledge: 2004.

. Diversity and citizenship education: global perspectives. San Francisco: Jossey-Bass,

BANKS, James. Multicultural education: historical development, dimensions and practice. In: BANKS, James; BANKS, Cherry A. McGee (org.). Handbook of research on multicultural education. San Francisco: Jossey-Bass, 2004.

BOND, Horace. M. Negro education in Alabama: A study in cotton and steel. Washington, DC: The Associated Publishers, 1939.

CASTAGNO, Angelina. E., \& BRAYBOY, Bryan. M. J. Culturally responsive schooling for Indigenous youth: A review of the literature. Review of Educational Research, 78, 941-993, 2008. BLANCHARD, P. et all. La fracture colonial: la société française au prisme de l'héritage colonial. Paris: Édition La Découverte/Poche, 2006.

BRASIL. Parâmetros Curriculares Nacionais: História e Geografia / Secretaria de Educação Fundamental. Rio de Janeiro: DP\&A, 2000. 
Lei 10.639 de 9 de janeiro de 2003. D.O.U. de 10 de janeiro de 2003.

Diretrizes Curriculares Nacionais para a Educação das Relações Étnico-Raciaise para o Ensino de História e Cultura Afro-Brasileira e Africana. Brasília: MEC, 2004.

BRINPAUM, Yael; MOGUEROU, Laure.; PRIMON, Jean-Luc. Parcours et expériences scolaires des jeunes descendants d'immigrés en France. In: BEAUCHEMIN, C. HAMEL, C.; SIMON, P. (Coord.) Trajectories et Origines. Enquête sur la diversité des populations en France. Premiers Résultats. Paris: Editions de l’INED, n. 168, 2010.

BRZEZINSKI, Iria. A pesquisa sobre formação de profissionais da educação em 25 anos de história. 30 ${ }^{a}$. Reunião Anual da ANPED, Caxambu, 2007.

BRZEZINSKI, Iria; GARRIDO, Elsa. Análise dos trabalhos do GT Formação de Professores: o que revelam as pesquisas do período 1992-1998. Revista Brasileira de Educação, n. 18, 2001.

CAVALLEIRO, Eliane dos Santos. Do silêncio do lar ao silêncio escolar: racismo, preconceito e discriminação na educação infantil. 1. ed. São Paulo: Contexto, 2000.

COELHO, Wilma B. Só de corpo presente: o silêncio tácito sobre cor e relações raciais na formação de professores no estado do Pará. Revista Brasileira de Educação, Rio de Janeiro: ANPED; Campinas: Autores Associados, v. 12, n. 34, p.39-56, jan./abr. 2007.

COELHO, Wilma de Nazaré Baía, SANTOS, Raquel Amorim Dos, SILVA, Rosângela Maria de Nazaré Barbosa e. Educação e relações raciais: estado da arte em programas de pós-graduação em educação (2000-2010).In: Anais do Copene. Ações afirmativas: cidadania e relações étnicoraciais, Belém-PA. UFPA, 2014.

CORENZA, Janaina de Azevedo. Formação inicial de professores: conversas sobre relações raciais e educação. Curitiba: Appris, 2018.

COUTO, Regina Célia. Formação de professores/as, multiculturalismo e ensino de história: desafios e possibilidades. 26a. Reunião Anual da Associação Nacional de Pesquisa em Educação, Poços de Caldas, 2003.

CUNHA, Maria Isabel. O tema da formação de professors: trajetórias e tendências do campo na pesquisa e na ação. Educ. Pesqui., vol. 39, n. 3 São Paulo, 2013.

DEBARBIEUX, Éric; TICHIT, Laurence. Ethnicité, punitions et effect-classe. Migrants Formation, n. 109, 1997.

DEBARBIEUX, E.; GARNIER, A; MONTOYA, Y.; TICHIT, L. La violence en milieu scolaire, Le désordre des choses. Paris: ESF, 1999.

DIM. Plan national d'action contre le racisme et l'antisémitisme 2012 - 2014. Delégation interministérielle à la lutte contre le racisme et l'antisémitisme, 2012. http:// www.gouvernement.fr/gouvernement/plan-national-d-action-contre-le-racisme-et-1antisemitisme-2012-2014. Acesso em 19/02/2019. 
DHUME, Fabrice. De l'(in)égalité de traitement selon "l'origine". Paris: Editions La Documentation Française, 2011.

DU BOIS, William E. B. Black reconstruction in America, 1860-1880. New York: Harcourt, 1935.

FASSIN, Didier. L'invention française de la discrimination. Revue française de science politique. v. 52, n. $04,2002$.

FASSIN, Didier. Ni race, ni racisme. Ce que racialiser veut dire. In: FASSIN, D; FASSIN, E. (dir.). De la question sociale à la question raciale. Représenter la societé française. Paris: La Découverte, 2010.

FELOUZIS, Georges; LIOT, Francoise; PERROTON, Joelle. L'Apartheid Scolaire, Enquetê sur la ségrégation ethnique dans les collèges. Paris: Édtitions Point Seuil, 2005.

FRANCIS, Véronique. Estereótipos e discriminação étnico-racial em e através dos livros ilustrados infant-juvenis. Revista Eletrônica de Educação, v. 9, n. 2, 2015.

GAUTHIER, C. et al. Por uma teoria da pedagogia. Ijuí: Unijuí, 1998.

GAY, Geneva. Ethnic Minority Studus. How Widespread? How Successful? Educational Leadership, 29, p. 108-12, 1971.

GAY, Geneva. Coming of age ethnically: Teaching young adolescents of color. Theory Into Practice, 33, 149-155, 1994.

GOMES, Nilma Lino. Diversidade étnico-racial: por um projeto educativo emancipatório. Retratos da Escola, v. 2, 2008.

GONÇALVES, Luiz Alberto Oliveira. O silêncio: um ritual pedagógico a favor da discriminação racial: (um estudo acerca da discriminação racial como fator de seletividade na escola pública de primeiro grau - 1a a 4a série). Dissertação (Mestrado). Faculdade de Educação da Universidade Federal de Minas Gerais, UFMG, 1985.

GRANT, Carl A. Education that is multicultural. Isn't that what we mean? Journal of Teacher Education, 29, p. 45-48, 1978.

JESUS, Rita de Cássia Dias Pereira de. De como tornar-se o que se é: narrativas implicadas sobre a questão étnico-racial, a formação docente e as políticas para equidade.2007. $214 \mathrm{f}$. Tese (Doutorado em Educação) -Faculdade de Educação da Universidade de São Paulo, São Paulo, 2007.

KING, Joyce Elaine. Culture-centered knowledge: Black studies, curriculum transformation, and social action. In: BANKS, James; BANKS, Cherry A. McGee. Handbook of research on multicultural education. San Francisco: Jossey-Bass, 2004. 
KYMLICKA, Will. Multicultural citizenship. New York. Oxford University Press, 1995.

LADSON-BILLINGS, Gloria. But that's just good teaching! The case for culturally relevant pedagogy. American Educational Research Journal, 32, 1995.

LADSON-BILLINGS, Gloria. New directions in multicultural education: complexities, boundaries, and critical race theory. In: BANKS, James; BANKS, Cherry A. McGee. Handbook of research on multicultural education. San Francisco: Jossey-Bass, 2004.

LORCERIE, Françoise. La scolarisation des enfants de migrants: fausses questions et vrais problèmes. In: DEWITTE, Ph. (dir.) Immigration et intégration, l'état des savoirs. Paris: La Découverte, 1999.

LORCERIE, Françoise; PHILLIPP, Marie-Gabrielle. Enseigner en milieu ethnicisé face à la discrimination. Actes duCOLLOQUE DU RÉSEAU INTERCULTUREL ET ÉDUCATION, Ville-École-Intégration Enjeux, hors-série n.6, décembre, 2002.

MARIANO, Luiz Sena. Formação docente e multiculturalismo em pesquisas brasileiras: reflexões iniciais. $32^{a}$. Reunião Anual da ANPED, Caxambu, 2009.

MATTAI, P. Rudy. Rethinking the Nature of Multicultural Education: Has it Lost its Focus or is it Being Misused? Journal of Negro Education V. 61, n. 1, 1992. Disponível em: http://www.jstor.org/stable. Acessado em: Outubro de 2009.

MONTEIRO, Rosana Batista. A educação para as relações étnico-raciais em um curso de Pedagogia : estudo de caso sobre a implementação da Resolução CNE/CP 01/2004. 2010. 267f Tese (Doutorado em Educação) Universidade Federal de São Carlos, São Carlos-SP.

MUNANGA, Kabengele. Superando o racismo na escola. Brasília: MEC, Secretaria de Educação Fundamental, 2001.

NDIAYE, Pap. Questions de couleur. Histoire, idéologie et pratiques du colorisme. In: FASSIN D.; FASSIN E. (dir.) De la question sociale à la question raciale. Représenter la société française. Paris: La Découverte, 2006.

NDIAYE, Pap. La condition noire. Essai sur une minorité française. Paris: Calmann-Lévy, 2008.

NÓVOA, Antonio. A formação do professor: um debate necessário. Edto Porto, 1995.

NUSSBAUM, Martha. Patriotism and cosmopolitanism. In For love country. Boston: Beacon Press, 2002.

OLIVEIRA, Luiz Fernandes de. Histórias da África e dos africanos na escola: as perspectivas para a formação dos professores de história quando a diferença se torna obrigatoriedade curricular. 2010. Tese (Doutorado em Educação) - Pontifícia Universidade Católica do Rio de Janeiro, 2010. 
PAULA, Benjamin Xavier de. ; GUIMARÃES, Selva. 10 anos da lei federal no 10.639/2003 e a formação de professores: uma leitura de pesquisas científicas. Revista Educ. Pesquisa., São Paulo, v. 40, n. 2, p. 435-448, abr./jun. 2014.

Disponível em: http://www.scielo.br/pdf/ep/v40n2/v40n2a09.pdfAcesso em: 20/07/2019.

PAYET, Jean-Paul. Collèges de banlieue. Ethnographie d'un monde scolaire. Paris: Méridiens Klinkc-sieck, 1995.

. La catégorie ethnique dans l'espace relationnel des collèges de banlieue: entre censure et soulignement. In: AUBERT, F; TRIPIER, M; VOURC'H, F (dir.) Jeunes issus de l'imigration. De l'école à l'emploi. Paris: CIEMI-L'Harmattan, 1997.

La ségrégation scolaire. Une perspective sociologique sur la violence à l'école. Revue Française de Pédagogie. 123, 1998.

PIMENTA, Selma. G.; ANASTASIOU, L. G. Docência no ensino superior. São Paulo: Cortez, 2002.

PINHEIRO, Juliano Soares. Aprendizagens de um grupo de futuros(as) professores(as) de química na elaboração de conteúdos pedagógicos digitais: em face dos caminhos abertos pela lei federal no 10.639 de 2003. Uberlândia: Programa de Pós-graduação em Química da Universidade Federal de Uberlândia - UFU, 2009. (Dissertação de Mestrado).

SANTOS, Aldenir dias dos. Percepção das formandas e dos formandos do ano 2003 do curso de pedagogia da UNIMEP, sobre questões referentes às relações raciais na prática docente. 2003. Tese (Doutorado em Educação) - Universidade Metodista de Piracicaba, Piracicaba, 2003.

SHULMAN, L. Knowledge and teaching: foundations of the new reform. Harvard Educational Review, v. 57, n. 1, p. 1-22, Feb. 1987.

SILVA, Alexandra Lima. Formação de professores e relações étnico-raciais: um balanço da produção acadêmica. Anais do Copene Ações. Afirmativas: cidadania e relações étnico-raciais, Belém, UFPA, 2014.

SILVA, Douglas Verrangia C. da. A educação das relações étnico-raciais no ensino de Ciências: diálogos possíveis entre Brasil e Estados Unidos. Tese de Doutorado. Programa de PósGraduação em Educação. São Carlos: UFSCar, 2009.

SILVA, Petronilha B. G. ; GOMES, Nilma Lino (Org.). Experiências Étnico-culturais para a formação de professores, Belo Horizonte: Autêntica, 2002.

SILVA, Rafael Ferreira. Educando pela diferença para a igualdade: professores, identidade profissional e formação continuada. 2010, $316 f$ Dissertação (Mestrado em Educação) Universidade de São Paulo.

SILVÉRIO, Valter R. Transnacionalismo negro, diáspora africana: desafios para uma nova imaginação sociológica. Tese (Titular da Carreira do Magistério Superior). Departamento de Sociologia/UFSCar, 2018. 
SISS, Ahyas. Multiculturalismo, educação brasileira e formação de professores: verdade ou ilusão? In: $28^{a}$ Reunião Anual da ANPE, GT 21-Afro-brasileiros e Educação, Caxambu, 2005.

SOUZA, Elisabeth F. Repercussão do discurso pedagógico sobre relações raciais nos PCNs. In: CAVALLERO, E. (org) Racismo e anti-racismo na educação: repensando nossa escola. São Paulo: Summus, 2001.

SWARTZ, Ellen. Diversity: gatekeeping knowledge and maintaining inequalities. Review of Educational Research. V. 79, n. 02, Junho, 2009. Disponível em: http://www.jstor.org/stable. Acessado em: Outubro de 2009.

TARDIF, M. et al. Formação dos professores e contextos sociais: perspectivas internacionais. Porto: Rés-Editora, 2001.

TARDIF, Maurice. Saberes Docentes e Formação Profissional. 2a edição. Petrópolis: Vozes, 2002.

Wesley, Charles H. Richard Allen: Apostle of freedom. Washington, DC: The Associated Publishers, 1935.

XAVIER, Giseli P. de M. A formação continuada dos profissionais da educação e o desafio de pensar multiculturalmente uma escola pública de qualidade. 30 ${ }^{a}$. Reunião Anual da ANPED, Caxambu, 2007.

Recebido 30/03/2020

Aprovado em 30/04/2020 